\title{
Collaboration As a Viable Approach for Making Astrophysics Research Accessible to the K-12 Community Through the Internet and the World Wide Web
}

\author{
By IS A BEL HAWKINS ${ }^{1}$, ROBYN BATTLE $E^{1,2}$ \\ AND MARLENE WILSO N
}

${ }^{1}$ UC Berkeley, Center for Extreme Ultraviolet Astrophysics, 2150 Kittredge Street, Berkeley, CA, 94720, USA

${ }^{2}$ UC Berkeley Graduate School of Education, Berkeley, CA, USA

${ }^{3}$ Fruitvale Elementary School, Oakland, CA, USA

\section{Introduction}

We describe a partnership approach in place at UC Berkeley's Center for Extreme Ultraviolet Astrophysics (CEA) that: (a) facilitates the adaptation of astrophysics data and information from NASA and other sources for use in the K-12 classroom, (b) facilitates scientists' participation in astronomy education, and (c) engages a sustained collaboration typically including personnel from research institutions, centers of informal science teaching such as museums and planetaria, university-based schools of education, and $\mathrm{K}-12$ schools. We are investigating several ways of engaging scientists in partnerships for the purpose of making their research results accessible in appropriate ways to the K-12 community via Internet and World Wide Web technologies. Our investigation addresses the hypothesis that the transition of scientific data and research results from the workplace to the classroom can be facilitated by the joint creation of curriculum materials by teams of cognitive experts, subject-matter experts, and teachers. In particular, we are investigating how space science, astronomy, and Earth science research results can be adapted through a partnership approach into more effective representations for use in the classroom. Our strategy for evaluating our partnership approach engaged the participation of personnel from scientific research institutions, centers of informal science learning, and schools. We describe several projects led by UC Berkeley's Center for EUV Astrophysics: "Science On-Line," "Science Information Infrastructure," and "Satellite Operations Class for Teachers." Our projects have two primary and complementary components, namely, implementation in school districts serving students with wide-ranging socio-economic backgrounds and a science education research component based on in-depth project evaluation. We describe several specific advantages that arise from a partnership approach in the context of using the Internet and the World Wide Web as relatively new authoring and representation media for K-12 curriculum materials.

\section{The Importance of Developing Collaborative Efforts in Astronomy Education}

The astrophysics community is increasingly interested in becoming involved in the education of today's students and is eager to share exciting space science results with the general public. Although it is sometimes feasible for institutes to create self-contained educational programs, this method is probably not the most efficient nor the most productive way of participating in educational processes. Often we find that institutes do not have a complete range of expertise in the fields of science, research, and education 
that responds to the needs of the varied $\mathrm{K}-12$ and general public communities. Thus it is imperative for quality space science education that organizations join together to build collaborations containing expertise in all of these essential fields. This important collaborative strategy (a) avoids duplication of effort, (b) allows each partner to operate primarily in their area of expertise, (c) provides a natural mechanism to translate cutting-edge research and technology into resources that respond to the needs of educators and students, (d) forms a multi-level resource network, which can be utilized in a most appropriate manner by district, school, teacher, student, and public audiences, (e) results in programs that contain substantive feedback and input from the K-12 and college-level educational communities, (f) creates an information flow which occurs in a smooth manner from research center to museums and intermediate astronomy education groups to the K-12 and college level community, and (g) results in programs which are more likely to reach diverse audiences.

\section{Theoretical Framework}

The introduction of technical innovations into the classroom has the potential to produce a dramatic redefinition of traditional roles for teachers and students blurring the boundaries between the processes of teaching and learning (Park \& Hannafin (1993)). Major emphasis has been given to more relevant curriculum and models of learning that more closely reflect scientific workplace learning (Becker 1972; Lave \& Wenger 1991; Collins, Brown, \& Newman 1989). Park \& Hannafin (1993) suggest that students and teachers benefit by learning how to use technological tools found in scientific, academic, and business workplaces. A specific scientific discipline has specialized and characteristic forms of discourse, including not only jargon, but ways in which research is carried out via the formulation of hypotheses and conjectures, the interplay between theory and observations, and the way in which new results are related to accepted knowledge (Schoenfeld $1985,1987)$. Thus, the creation of an effective scientific curriculum that reflects the practices of the workplace can benefit from the integral participation of subject-matter experts.

Use of technology in the classroom can foster an environment that more closely reflects the processes scientists use in doing research (Linn, diSessa, Pea \& Songer 1994). For instance, scientists rely on technological tools to model, analyze, and ultimately store data. Linn, diSessa, Pea \& Songer (1994) suggest that technological tools be introduced to students from the earliest years because of their ability to facilitate scientific modeling, scientific collaborations, and electronic communications in the classroom. Our investigation is motivated by the need for effective participation of scientists in K-12 education using a methodology that prevents duplication of effort.

\section{Brief Project Descriptions}

We briefly describe three projects that have served as the foundation for the UC Berkeley Center for EUV Astrophysics Education Program.

\subsection{Satellite Mission Class for Teachers}

This semester-long class is offered to in-service teachers through UC Berkeley Extended Education where teachers obtain university credit they can apply toward their professional development credential requirements. During this class, funded through NASA's IDEA program, teachers collaborate with scientists, technical personnel and undergraduate students from UC Berkeley/CEA, as well as with graduate students from the UC 
Berkeley Graduate School of Education. The teams work on development of lesson plans for the Internet/WWW based on the NASA EUVE and other satellite astronomy missions. Teachers learn about NASA missions and their data, the Internet, and the World Wide Web in the contextually-relevant process of lesson plan development, an important aspect of their professional growth. The sustained interactions with other professionals during the semester-long class results in a high level of training that the teachers take back to their schools and share with their peers.

\subsection{Science On-Line (SOL) Project}

The Center for Extreme Ultraviolet Astrophysics (CEA) at UC Berkeley received funding from NASA's Office of Space Science to support the Science On-Line - Earth and Space Science for the Classroom Project (SOL). Initiated in September 1994, SOL brings together formal and informal science centers, linking their unique and complementary assets. SOL joined the efforts of UC Berkeley's Center for Extreme Ultraviolet Astrophysics (CEA), the Lawrence Hall of Science and UC Museum of Paleontology, with the efforts of San Francisco's Exploratorium, and Chicago's Adler Planetarium for the purpose of creating on-line Internet-based resources for 6 th-12th grade teachers and students. The Science On-Line (SOL) Project serves as the foundation for its follow-up project, the Science Information Infrastructure, which is described below. SOL was designed to achieve the following goals:

(a) Build on the experiences gained from the Satellite Mission Class for Teachers to design a robust methodology for supporting teachers in the development of Internet-based science lesson plans.

(b) Create a robust learning process that allows teachers emerging from the project and its successor programs to assume mentoring roles to other members of the K-12 community.

(c) Make certain that as schools increasingly gain access to the Internet/WWW, K-12 educators and students will find appropriate resources that are constructed according to their particular needs and that can be integrated with the science curriculum.

\subsection{Science Information Infrastructure (SII) Project}

The SII is a consortium of science centers (museums) linked together to bring cutting edge science and the technology associated with science research to the public. The purpose of the project is to create a network of resources created by teams of teachers, science museum personnel, scientists and technical staff and hosted by science museums. The resources being created are intended for use by anyone, but especially in the classroom setting as well as for exploratory learning. In the SII model, the small, local focus teams of teachers and individuals from the science museums and partner research institutions create educational resources for science and math classes based on NASA remote-sensing data and related information and networked science research services. The life cycle of the materials and on-line tools involves testing in the classroom, evaluation, modification and revision and further testing in different environments. These resources are made available through the host museum, and coordinated nationwide during the course of the program. The SII is intended to build a sustainable framework for this process and accommodate new and experimental activities that use networked technology in innovative ways. The SII national partnership, funded by NASA High Performance Computing and Communications Division, includes the following members:

- Research Institutions: UC Berkeley Center for EUV Astrophysics, Smithsonian Astrophysical Observatory, Space Telescope Science Institute, National Air and Space Museum Center for Earth and Planetary Studies 
- Science Museums: Boston Museum of Science, Exploratorium, Lawrence Hall of Science, National Air and Space Museum, New York Hall of Science, Science Museum of Virginia

- Industry Partners: EOSAT, PacBell CalREN, Digital Equipment Corporation, Dun \& Bradstreet

\section{Key Elements of Our Partnership Model}

Essential elements of our model include:

(1) Engaging end-users (teachers and their students) in sustained interactions with scientists. This strategy enables teacher participants to assume peer-mentoring roles at school sites, and develops a critical mass of end-users.

(2) Allowing every member of the team (teacher, scientist, other educators) to contribute their unique expertise to the partnership. This strategy facilitates team interactions to occur on a level playing field, and prevents duplication of effort. Through this strategy, the developed resources benefit from both scientific and pedagogical expertise.

(3) Facilitating participation by scientists from other institutions within an established framework. Through this strategy, scientists can contribute their unique assets (data, research results, mentoring) with potentially large impact and multiplier effect, taking advantage of an existing end-user support structure. This strategy also provides scientists with meaningful opportunities for interacting with educators from formal and informal institutions.

Our model is leveraged as follows:

(a) Having science museums adopt our methodology, having museum personnel support teachers in the long-term development of Internet based materials, and featuring SII resources as part of museum-led teacher workshops.

(b) Through a tiered resource presentation structure that encourages independent teachers to use our materials to develop their own lesson plans.

\section{World Wide Web Information on the Science Education Program at CEA}

For more information and resources, access the UC Berkeley Center for EUV Astrophysics World Wide Web Education Server at:

http://www.cea.berkeley.edu/Education

\section{Results and Conclusions}

One of this investigation's main objectives is to bring the K-12 community into closer working relationships with the scientific community. The relationships established through our programs bring teachers into contact with research institution workplaces where they have access to scientists and gain exposure to the technology and thinking of scientific communities. Our projects are resulting in Internet-based lessons based on science data and information, and our investigation suggests that many of the science resources posted on the Internet need to be adapted for effective use in the K-12 classroom. Such adaptation of scientific Internet-based materials for the classroom appears to be best accomplished by a team approach that involves experts in science content, lesson development, and pedagogy. Project teams that work closely with scientists produce more conceptually robust lessons. Conversely, several Internet-based tools offered by various scientific institutions for use in a broad, non-research oriented context require at times significant 
adaptation by teacher developers for use in the classroom. The findings of this investigation are enabling us to develop a coherent team approach for facilitating the effective access and use of scientific data and research practices by the K-12 community. This methodology provides teachers with a science curriculum that engages their students in research-oriented classroom activities that take advantage of a technologically-rich environment. Our goal is to establish a robust methodology that provides the scientific community with a viable mechanism for sharing research results with a broader audience in educationally-relevant ways.

We acknowledge funding for our programs by the following sources:

- NASA High Performance Computing and Communications

- NASA Office of Space Science

- NASA IDEA

\section{REFERENCES}

BECKER, H.S., 1972, American Behavioral Scientist, 16, 85-105.

Collins, A., Brown, J.S. \& Newman, S., 1989, Cognitive apprenticeship: teaching the crafts of reading, writing, and mathematics. Knowing, Learning, and Instruction (ed. Resnick, L.B.). 453-494, Erlbaum, Hillsdale, N.J.

Lave, J. \& Wenger, E., 1991, Situated Learning: Legitimate Peripheral Participation. Cambridge University Press, Cambridge.

LinN, M., DISEsSA, A., PEA, R. \& SoNGER, N., 1994, Can Research on Science Learning and Instruction Inform Standards for Science Education? Journal of Science Education and Technology.

Park, I. \& Hannafin, M., 1993, Empirically-Based Guidelines for Design of Interactive Multimedia. Educational Technology Research and Development, 41(3), 63-85.

Schoenfeld, A. H., 1985, Mathematical Problem Solving. Academic Press, Orlando, Fl.

Schoenfeld, A. H., 1987, What's all the fuss about metacognition? In Cognitive Science and Mathematics Education ed. Schoenfeld, A.H., 189-216. Lawrence Erlbaum Associates, Hillsdale, NJ. 